\title{
Audit of EEG Reporting Temporal Abnormalities
}

\author{
Dang Khoa Nguyen, Marie-Eve Girard, Patrick Cossette, \\ Jean-Marc Saint-Hilaire
}

\begin{abstract}
Background: To ensure the overall quality of our electroencephalogram (EEG) laboratory, we decided to perform an audit of EEGs interpreted at our institution, focusing initially on EEGs reporting temporal abnormalities. Methods: Reports of all EEGs performed between January 1st and June 30th, 2006 were reviewed in order to identify tracings mentioning abnormalities in the temporal regions. These records were then independently reviewed by two epileptologists on two distinct occasions, separated by an interval of at least six months. If the recording was considered normal after this process, the cause for misinterpretation was identified and the patient's chart was reviewed to determine if he was epileptic or not based on available evidence until June 2009. Results: In the first half of 2006, 143 out of 773 EEGs mentioned temporal abnormalities (18.5\%). In general, intra- and interrater agreement ratios between our two epileptologists were moderate to substantial for normality, presence of epileptic activity and presence of slowing. Forty-five recordings $(31.5 \%)$ were reported as normal independently by them on two distinct sittings six months apart. The most common causes for misinterpretation were the presence of benign epileptiform variants, normal sharply contoured patterns of somnolence or hyperventilation. Chart review confirmed that most were non-epileptic patients (60\% non-epileptic, $27 \%$ epileptic, $13 \%$ unknown). Conclusion: Moderate to substantial intra- and interrater agreement as well as frequent misinterpretation of physiological variants indicate that some corrective measures need to be implemented to improve the consistency of EEG interpretation amongst our group of electroencephalographers.
\end{abstract}

RÉSUMÉ: Vérification de la notification d'anomalies temporales à l'EEG. Contexte : Nous avons décidé de procéder à la vérification des EEG interprétés à notre institution afin de nous assurer de la qualité globale de notre laboratoire d'EEG, en ciblant initialement les EEG qui rapportaient des anomalies temporales. Méthodologie : Tous les rapports d'EEG effectués entre le premier janvier et le 30 juin 2006 ont été révisés pour identifier les tracés mentionnant des anomalies dans les régions temporales. Ces dossiers ont ensuite été révisés par deux épileptologues à deux reprises, à six mois d'intervalle. Si l'enregistrement était considéré normal après cette étude, la cause de la mésinterprétation était identifiée et le dossier du patient était révisé afin de déterminer s'il était épileptique ou non, selon les données disponibles acquises jusqu'en juin 2009. Résultats : Au cours de la première moitié de 2006, 143 des 773 EEG mentionnaient des anomalies temporales $(18,5 \%)$. En général, le taux de concordance intra et inter observateurs entre nos deux épileptologues était de modéré à élevé en ce qui concerne la normalité, la présence d'activité épileptique et la présence de ralentissement. Quarante-cinq enregistrements $(31,5 \%)$ ont été rapportés comme normaux par chacun d'eux indépendamment, lors des deux lectures à six mois d'intervalle. Les causes les plus fréquentes de mésinterprétation étaient la présence de variantes épileptiformes bénignes, de tracés normaux de somnolence ou d'hyperventilation à l'aspect accentué. La revue de dossiers a confirmé que la plupart des patients n'étaient pas épileptiques (60\% non épileptiques, $27 \%$ épileptiques, $13 \%$ état inconnu). Conclusion : Une concordance modérée à élevée intra et inter observateurs ainsi qu'une mésinterprétation fréquente de variantes physiologiques indiquent que des mesures correctrices doivent être mises en place pour améliorer la cohérence des interprétations EEG au sein de notre groupe d'électroencéphalographistes.

Can. J. Neurol. Sci. 2010; 37: 819-825

The electroencephalogram (EEG) is a valuable neurodiagnostic tool in the evaluation of patients suspected of having epilepsy. A normal EEG does not necessarily exclude epilepsy but the detection of epileptiform abnormalities (such as spikes, sharp waves and spike-slow-wave discharges) indicates a seizure tendency which may support the clinical diagnosis of epilepsy and provide additional information regarding seizure type and focus.

Unfortunately, there is often considerable diversity among clinicians in the interpretation of tracings. Spikes, sharp waves or spike-slow-wave discharges are sometimes difficult to identify correctly. The disagreement regarding spike detection by different readers or by the same reader at different sittings is well documented ${ }^{1-5}$. There are several possible explanations for these disparities. Because of the lack of quantitative criteria, the

Service de neurologie, Centre hospitalier de l'Université de Montréal - Hôpital NotreDame, Montréal, Québec, Canada.

Received February 1, 2010. Final Revisions Submitted May 3, 2010.

Correspondence to: Dang K. Nguyen, Service de neurologie, Hôpital Notre-Dame du CHUM, 1560 rue Sherbrooke Est, Montréal, Québec, H2L 4M1, Canada. 
visual detection of spikes by a human reader is a purely perceptual, subjective and probabilistic phenomenon with each reader having his/her own spike feature definitions and personal ideology/threshold/caution level for declaring a transient potential as epileptic. Not all sharply contoured EEG potentials are associated with epileptic seizures ${ }^{6}$. There are indeed 'epileptiform variants' which appear sharp, paroxysmal, rhythmic, or sustained, but do not indicate a seizure tendency. Over the years, they have been labeled variously as 'epileptiform activity in the EEG of non-epileptic subjects', 'nonepileptogenic epileptiform electroencephalographic activity' and more commonly 'benign epileptiform variants' $(\mathrm{BEVs})^{7,8}$. Several BEVs have been described such as the benign sporadic sleep spikes (BSSS) (syn small sharp spikes, benign epileptiform transients of sleep), the wicket waves (syn wicket spikes), the 14 and $6 \mathrm{~Hz}$ positive spikes (syn ctenoids) ${ }^{9}$, the $6 \mathrm{~Hz}$ spike-waves (syn phantom spike and wave), the rhythmic temporal theta burst of drowsiness (RTTD) (syn psychomotor variant, rhythmic midtemporal discharges), and the subclinical rhythmic electroencephalographic discharges of adults (SREDA) ${ }^{10}$. Although breach rhythms are not typically considered a benign variant, the presence of a skull defect can considerably complicate EEG interpretation as physiological and benign variants such as wicket waves, RTTD or $m u$ rhythms appear sharper and more prominent. It is important to recognize these BEVs as they may be construed as epileptic abnormalities and lead to misdiagnosis of epilepsy ${ }^{11-13}$. Physician training and experience may partly explain differences in interpretations ${ }^{5}$. Neurologists having completed a clinical neurophysiology or epilepsy fellowship, neurologists specialized in a specialty other than epilepsy, general neurologists, paediatricians or psychiatrists may differ in EEG interpretation expertise from center to center.

For patients and their physicians who requested the EEG, the reliability of the interpretation from the EEG laboratory is of great importance. To ensure the overall quality of our EEG laboratory, we decided to perform an audit of all EEGs interpreted in the first half of 2006 at our institution. Our initial objective was to assess the rate of EEGs misinterpreted with temporal abnormalities due to the presence of BEVs. Because there is no gold standard against which our electroencephalographers' interpretation can be definitively evaluated, we elected to consider only EEGs which were declared normal after independent review by two experienced epileptologists in two different sittings. This also allowed assessment of intra- and interrater reliability between these two epileptologists. Determining how frequent BEVs are misinterpretated for an abnormality and establishing intra- and interrater variability is important to determine if corrective measures need to be implemented.

\section{METHODS}

\section{EEG laboratory}

Since 2001, EEGs have been captured digitally. Gold plated EEG electrodes (Astro-Med Inc, USA) are positioned according to the international 10-20 system, fixed to the skin with Elifix paste (Nihon Kohden, Japan) and connected to a 32-channel headbox from Stellate (Stellate Systems Inc., Canada). Twentynine channels of recording were obtained from these scalp electrodes. Impedance was kept below $5 \mathrm{~K} \Omega$, channel sampling rate was set at $200 \mathrm{~Hz}$, and an anti-aliasing filter of $70 \mathrm{~Hz}$ and a low frequency filter of $0.1 \mathrm{~Hz}$ were used. The guidelines of the American Society of Clinical Neurophysiology ${ }^{14}$ and the Task Force of the Canadian Society of Clinical Neurophysiologists ${ }^{15}$ were utilized for performing EEG recordings. Every wake EEG recording lasted 35 minutes and included basal recording with eye opening and closing maneuvers, three distinct 3 minutehyperventilation epochs, intermittent light stimulation with 15 seconds (s) flashing sequences from 4 to $22 \mathrm{~Hz}$. Zygomatic subtemporal electrodes were used but not sphenoidal, nasopharyngeal, nor foramen ovale electrodes. The recordings are reviewed by one of eleven neurologists, four of whom are epileptologists. The remainder have an academic practice concentrating on neuromuscular disorders, multiple sclerosis, dementia or movement disorders. All have been in practice for a minimum of six years. The video screen display has a horizontal scaling equivalent of $25-35 \mathrm{~mm} / \mathrm{s}$ and a screen resolution of 1280 x 1024 pixels. The recording sensitivities are initially adjusted visually by the EEG technologist (on average 7.5 $\mathrm{uV} / \mathrm{mm}$ ). Long-term archiving is accomplished using writable CDs and DVDs (CD-R/DVD-R) to store digital EEG recordings. The final typed EEG report is filed in the patient's medical chart. A copy is kept in the EEG laboratory.

\section{EEG selection}

Interpretations of all EEGs performed at Notre-Dame hospital between January 1st, 2006 and June 30th, 2006 were reviewed in order to identify reports mentioning abnormalities in the temporal regions. These records were then independently reviewed by two electroencephalographers trained in epilepsy (DKN, J-MS-H) on two distinct occasions, separated by an interval of at least six months. Both electroencephalographers were part of the original group that read the records. They had access to a short comment entered by the EEG technician at the beginning of the recording which would usually (but not always) include information such as age, reason for test, level of cooperation and medication. We used as a reference the Atlas of Adult Electroencephalography (2nd edition) by Blume, Kaibara and Young ${ }^{16}$. The EEGs were classified into four categories: (0) uninterpretable due to excessive artefact; (1) presence of epileptic activity (sharp waves, spikes, spike-slow-wave discharges), which was invariably associated with focal slowing; (2) abnormal slowing (focal or diffuse) without epileptic activity; (3) normal (including benign epileptiform variants); (4) suspicious for epileptic abnormality. If the recording was considered normal after review, the electroencephalographers attempted to determine why the tracing was originally reported to have temporal abnormalities. Charts of patients whose EEG were interpreted as normal by both electroencephalographers on two distinct sittings were reviewed by a third party (MEG) to determine if the patient was epileptic or not based on available evidence until June 2009. Permission to review EEG interpretations, recordings and patient charts was granted by the Centre Hospitalier de l'Université de Montréal Institutional Review Board. 


\section{Statistical analysis}

The intra- and interrater reliability were expressed in terms of kappa. The kappa statistic was used to adjust the observed agreement for chance. The kappa statistic is defined as $\left(\mathrm{P}_{\text {observed }}\right.$ $\left.-\mathrm{P}_{\text {chance }}\right) /\left(1-\mathrm{P}_{\text {chance }}\right)$, where $\mathrm{P}_{\text {observed }}$ is the percent observed agreement and $\mathrm{P}_{\text {chance }}$ is the percent agreement expected to occur by chance alone. Kappa equals zero when observed agreement and agreement by chance do not differ (the agreement is not better than would be expected by chance alone), and assumes increasingly positive values, with a maximum of +1 , when observed agreement exceeds chance. All statistical analyses concerning kappa coefficients were done using SAS software, version 9.1 (SAS Institute Inc, Cary, NC). Agreement was expressed in categories according to Landis and Koch ${ }^{17}$ : poor $<0$; slight 0-0.20; fair 0.21-0.40; moderate 0.41-0.60; substantial (suboptimal) 0.61-0.80; almost perfect $>0.80$.

\section{RESULTS}

\section{EEG selection}

Between January 1st, 2006 and June 30th, 2006, 773 EEGs were performed in our laboratory. Patients' age ranged from 17 to 94 years, with a mean age of 54 years. Half of the patients were between 17-55 years and the other half 56 years or older. Patients were referred for a variety of reasons: seizure disorders, suspicious spells, alteration of consciousness, psychological or behavioural symptoms, delirium, dementia. After reviewing the initial interpretations, 143 EEG recordings reporting temporal abnormalities were found (18.5\%).

\section{Review of selected EEG by two electroencephalographers trained in epilepsy}

Complete results of the interpretation by both electroencephalographers on two different sittings separated by at least six months is available as supplemental data (Appendix). The first electroencephalographer (DKN) classified recordings during his first reading session as: uninterpretable in $1 / 143$ (0.7\%), epileptic in $41 / 143(28.7 \%)$, slow in $23 / 143(16.1 \%)$, normal in $67 / 143(46.9 \%)$, and suspicious in $11 / 143(7.7 \%)$. In his second assessment of the same EEGs six months later, respective rates were $1.4 \%, 30.1 \%, 9.8 \%, 45.5 \%$ and $13.3 \%$. Overall, DKN classified the EEG in a different category than on the first reading session on 30 occasions (21\%). The second electroencephalographer (J-MS-H) reported on his first session that tracings were uninterpretable in $6 / 143(4.2 \%)$, epileptic in $28 / 143(19.6 \%)$, slow in $18 / 143(12.6 \%)$, normal in $69 / 143$ $(48.3 \%)$ and suspicious in $22 / 143(15.4 \%)$. Respective rates upon his second reading session six months later were $0.7 \%$, $28.7 \%, 18.2 \%, 45.5 \%$ and $7.0 \%$. Overall, the second electroencephalographer (J-MS-H). classified the EEG in a different category than on the first reading session in 50 instances $(35 \%)$. Scenarios could include recordings initially said to contain spikes (Category 1) or with suspicious epileptiform activity (Category 4) along with focal slowing which were later declared to only have focal slowing (Category 2 ); pathological slow waves (Category 2) which could later be declared as physiological (Category 4) and vice-versa, transient potentials initially declared as a benign epileptiform variant
(Category 3) which could later be interpreted as epileptic (Category 1) or suspicious (Category 4) and vice-versa; recordings which were declared as uninterpretable initially (Category 0) which were later deemed to have sufficient epochs to categorize otherwise.

\section{Intra- and interrater analyses}

Tables 1 and 2 illustrate how often the first and second electroencephalographers respectively agreed from the first to the second reading session on (a) whether the recording was normal (Category 3 ) or not [Categories 1 (epileptic), 2 (slowing) and 4 (suspicious)]; (b) the presence of epileptic activity (Category 1) or not [Categories 2 (slowing), 3 (normal) and 4 (suspicious)]; (c) and the presence of pathological slow waves [Categories 1 (epileptic) or 2 (slowing)] or not [Categories 3 (normal) and 4 (suspicious)]. Tables 3 and 4 illustrate how often both electroencephalographers agreed on their first and second reading sessions respectively over the same conclusions as above, i.e. normal or abnormal, presence of epileptiform activity or not, presence of pathological slowing or not.

For the first electroencephalographer (DKN), intraobserver agreement, measured with the kappa statistic, was substantial for normal vs abnormal $(\mathrm{k}=0.75)$, substantial for the presence of epileptic activity or not $(\mathrm{k}=0.80)$ and almost perfect for the presence of pathological slowing $(=0.81)$. For the second electroencephalographer (J-MS-H), intraobserver agreement was substantial for normal vs abnormal $(\mathrm{k}=0.62)$, moderate for the presence of epileptic activity or not $(\mathrm{k}=0.60)$ and moderate for the presence of pathological slowing $(\mathrm{k}=0.44)$. Disagreement on the presence of epileptic activity or not occurred in the presence of a unique but well-defined spike, a few but ill-defined sharp potentials, presence of a possible benign epileptiform variant, or presence of a skull defect with a breach rhythm. Disagreement on the presence of abnormal slowing or not were frequently caused by scoring differently, from one reading to the other, sharply contoured slow waves during hyperventilation or drowsiness, and/or in elderly patients.

Interobserver consistency for the first reading session was substantial for declaring a recording normal or abnormal $(\mathrm{k}=$ $0.66)$, moderate for the detection of epileptic activity $(\mathrm{k}=0.58)$ and substantial for the detection of abnormal slowing $(\mathrm{k}=0.65)$. With the second reading, interobserver agreement was substantial for all three conclusions $(\mathrm{k}=0.61,0.63$ and 0.63 respectively). Disagreement between both electroencephalographers occurred in the interpretation of slow waves as pathological vs physiological and in the scoring of sharp potentials as clearly epileptic vs only suspicious or a benign variant.

\section{Causes for misinterpretation}

Forty-five recordings (31.5\%) were reported as normal independently by our two epileptologists-electroencephalographers on two distinct sittings six months apart. From this subset of recordings we could reasonably consider as truly normal, we tried to assess why the original readers reported temporal abnormalities. In two cases, the original reader concluded there was an epileptic abnormality. In four cases, the original reader simply mentioned the presence of a single 
Table 1: Intraobserver agreement and kappa statistics for first electroencephalographer (DKN)

\begin{tabular}{|c|c|c|c|c|c|c|}
\hline \multirow[b]{3}{*}{ 1st session } & \multicolumn{6}{|c|}{ 2nd session } \\
\hline & \multicolumn{2}{|c|}{ Normal } & \multicolumn{2}{|c|}{ Epileptic } & \multicolumn{2}{|c|}{ Slowing } \\
\hline & Yes & No & Yes & No & Yes & No \\
\hline Yes & 57 & 10 & 36 & 5 & 54 & 10 \\
\hline No & 8 & 68 & 7 & 95 & 3 & 76 \\
\hline Pobserved & \multicolumn{2}{|c|}{$87.41 \%$} & \multicolumn{2}{|c|}{$91.61 \%$} & \multicolumn{2}{|c|}{$90.91 \%$} \\
\hline Pchance & \multicolumn{2}{|c|}{$50.29 \%$} & \multicolumn{2}{|c|}{$58.50 \%$} & \multicolumn{2}{|c|}{$51.06 \%$} \\
\hline Kappa & \multicolumn{2}{|c|}{0.7468} & \multicolumn{2}{|c|}{0.7978} & \multicolumn{2}{|c|}{0.8142} \\
\hline SE Kappa & \multicolumn{2}{|c|}{0.0558} & \multicolumn{2}{|c|}{0.0556} & \multicolumn{2}{|c|}{0.0489} \\
\hline
\end{tabular}

poor < 0; slight 0-0.20; fair 0.21-0.40; moderate 0.41-0.60; substantial $0.61-0.80 ;$ almost perfect $>0.80$

temporal sharp wave. For the remaining cases, the original reader used terms such as 'irritative, paroxysmal, potentially epileptic'. Our two electroencephalographers identified the following potential explanations (more than one could apply for each patient) to the original misinterpretation: RTTD (18), wicket spikes (7), BSSS (5), SREDA (4), breach rhythms (3), somnolence patterns (epochs of asymmetric theta slowing or delta bursts in drowsiness) (12), excess use of high-frequency filters in the presence of electrode artifacts or muscle activity (4) prominent photic response (2), normal sharply countoured hyperventilation response (2), asymmetry of alpha rhythm not exceeding $50 \%$ (3). Charts of these individuals were reviewed to determine if they were epileptic or not in light of their past medical history, details of the events leading to the EEG and the evolution in the subsequent two and a half years since the EEG. Twenty-seven of $45(60 \%)$ were considered not to be epileptic, 12 were epileptic $(27 \%)$. In the remaining six $(13 \%)$, there was

Table 3: Interobserver agreement and kappa statistics between both electroencephalographers (1st reading)

\begin{tabular}{l|l|l|l|l|l|l}
\hline & \multicolumn{5}{c|}{ 2e observer } \\
\hline & \multicolumn{2}{|c|}{ Normal } & \multicolumn{2}{c}{ Epileptic } & \multicolumn{2}{c}{ Slowing } \\
\hline 1st observer & Yes & No & Yes & No & Yes & No \\
\hline Yes & 56 & 11 & 25 & 17 & 43 & 21 \\
\hline No & 13 & 63 & 6 & 95 & 3 & 76 \\
\hline Pobserved & \multicolumn{2}{|c|}{$83.22 \%$} & \multicolumn{2}{|c|}{$83.92 \%$} & \multicolumn{2}{c}{$83.22 \%$} \\
\hline Pchance & \multicolumn{2}{|c|}{$50.11 \%$} & \multicolumn{2}{c|}{$61.69 \%$} & \multicolumn{2}{c}{$51.87 \%$} \\
\hline Kappa & \multicolumn{2}{|c|}{0.6636} & \multicolumn{2}{c|}{0.5802} & \multicolumn{2}{c|}{0.6513} \\
\hline SE Kappa & \multicolumn{2}{|c|}{0.0626} & \multicolumn{2}{c|}{0.0770} & \multicolumn{2}{c}{0.0626} \\
\hline
\end{tabular}

poor < 0; slight 0-0.20; fair 0.21-0.40; moderate 0.41-0.60; substantial $0.61-0.80$; almost perfect $>0.80$
Table 2: Intraobserver agreement and kappa statistics for second electroencephalographer (J-MS-H)

\begin{tabular}{|c|c|c|c|c|c|c|}
\hline \multirow[b]{3}{*}{ 1st session } & \multicolumn{6}{|c|}{ 2nd session } \\
\hline & \multicolumn{2}{|c|}{ Normal } & \multicolumn{2}{|c|}{ Epileptic } & \multicolumn{2}{|c|}{ Slowing } \\
\hline & Yes & No & Yes & No & Yes & No \\
\hline Yes & 54 & 15 & 24 & 4 & 37 & 9 \\
\hline No & 12 & 62 & 17 & 98 & 30 & 67 \\
\hline Pobserved & \multicolumn{2}{|c|}{$81.12 \%$} & \multicolumn{2}{|c|}{$85.31 \%$} & \multicolumn{2}{|c|}{$72.73 \%$} \\
\hline Pchance & \multicolumn{2}{|c|}{$50.13 \%$} & \multicolumn{2}{|c|}{$62.98 \%$} & \multicolumn{2}{|c|}{$51.12 \%$} \\
\hline Kappa & \multicolumn{2}{|c|}{0.6214} & \multicolumn{2}{|c|}{0.6034} & \multicolumn{2}{|c|}{0.4420} \\
\hline SE Kappa & \multicolumn{2}{|c|}{0.0656} & \multicolumn{2}{|c|}{0.0763} & \multicolumn{2}{|c|}{0.0724} \\
\hline
\end{tabular}

poor < 0; slight 0-0.20; fair 0.21-0.40; moderate 0.41-0.60; substantial $0.61-0.80$; almost perfect $>0.80$

not enough data to make such an assessment (e.g. patients referred from private clinics with no clinical information in the hospital's chart).

\section{Discussion}

The Notre-Dame EEG laboratory (Montreal, Canada) has been performing recordings since 1946 and serves a large population of all ages living in and around the metropolitan area. Excluding continuous video-EEG recordings, the laboratory performs close to 1500 routine EEGs annually. To heighten selfscrutiny and promote constructive feedback, we proceeded with an audit of EEG interpretation in our laboratory, starting with the review of all EEGs performed in the first half of 2006 which reported temporal abnormalities. Results indicate that some corrective measures need to be implemented to improve the consistency of EEG interpretation among our group of electroencephalographers.

Table 4: Interobserver agreement and kappa statistics between both electroencephalographers ( 2 nd reading)

\begin{tabular}{l|l|l|l|l|l|l|l}
\hline & \multicolumn{5}{c|}{ 2e observer } \\
\hline & \multicolumn{2}{|c|}{ Normal } & \multicolumn{2}{c|}{ Epileptic } & \multicolumn{2}{c}{ Slowing } \\
\hline 1st observer & Yes & No & Yes & No & Yes & No \\
\hline Yes & 51 & 14 & 31 & 12 & 49 & 8 \\
\hline No & 14 & 64 & 10 & 90 & 18 & 68 \\
\hline Pobserved & \multicolumn{2}{|c|}{$80.42 \%$} & \multicolumn{2}{c|}{$84.62 \%$} & \multicolumn{2}{c|}{$81.82 \%$} \\
\hline Pchance & \multicolumn{2}{|c|}{$50.41 \%$} & \multicolumn{2}{c|}{$58.50 \%$} & \multicolumn{2}{c|}{$50.64 \%$} \\
\hline Kappa & \multicolumn{2}{|c|}{0.6051} & \multicolumn{2}{c|}{0.6293} & \multicolumn{2}{c|}{0.6317} \\
\hline SE Kappa & \multicolumn{2}{|c|}{0.0669} & \multicolumn{2}{c|}{0.0717} & \multicolumn{2}{c}{0.0646} \\
\hline
\end{tabular}

poor < 0; slight 0-0.20; fair 0.21-0.40; moderate 0.41-0.60; substantial $0.61-0.80$; almost perfect $>0.80$ 
Our study revealed moderate to 'borderline' substantial agreement ( $\mathrm{k}$ range $0.58-0.66$ ) between two electroencephalographers trained in epilepsy on the normality of the test, presence of epileptic activity and presence of pathological slowing. This is not necessarily surprising as other studies have reported similar results (albeit in variable patient populations). Van Donselaar et al ${ }^{18}$ reported moderate agreement on normality and presence of epileptiform activity among four experienced clinical neurophysiologists each reading 25 standard and 25 sleep deprived EEGs of adult patients with untreated idiopathic first seizures. Piccinelli et al ${ }^{19}$ assessed the level of agreement in the interpretation of EEG records of patients with childhood idiopathic epilepsy by different experienced readers working in three child neurology tertiary centers and found poor to slight interrater agreement for two of the three pairs of readers when assessing background activity in awake EEG but substantial agreement for the presence of interictal discharges. As noted also in prior studies, our interrater agreement for epileptiform activity slightly improved on the second reading most likely because both electroencephalographers had discussed together the difficulties they faced in classifying certain sharp potentials in the first reading session. It can be reasonably assumed however that the interrater kappa values are lower in real clinical practice with a higher number of electroencephalographers with varying experience in EEG interpretation and area of subspecialty and perhaps not the same care our electroencephalographers gave in the interpretation of the EEGs for the sake of this research study.

More importantly however is the fact that close to a third of the recordings in this audit were initially reported to have temporal abnormalities though both our reviewers independently found them to be consistently normal on two separate reading sessions. The identified causes for the misinterpretations were in order of frequency the presence of benign epileptiform variants (especially RTTD, BSSS and wickets), physiological sharply contoured potentials during drowsiness and hyperventilation, excess use of high-frequency filters especially in the presence of breach rhythm and excessive muscular or electrode artifacts.

Several measures can be taken to improve the overall quality of EEG interpretation in our laboratory. Already, a formal presentation during neurology grand rounds was done during which results of the audit were shared to all members of the service followed by a brief review of common benign epileptiform variants. A discussion ensued among electroencephalographers on the causes of intra- and interrater reliability and measures to enhance them. General guidelines were established such as avoiding the use of high-frequency filters to prevent misconstruing artefacts for epileptiform activity, the necessary use of referential recording to the ipsilateral and contralateral ears to enhance detection of benign epileptiform variants, the harmonization of focal slowing gradation, the establishement of a consensus on the use of certain words such as 'irritative', 'paroxysmal', 'potentially epileptiform', the decision to adjust our personal thresholds to favor a higher specificity rather than a higher sensitivity in EEG interpretation. An EEG journal club every two months will be initiated to review interesting EEG recordings. Examples of benign epileptiform variants will be posted in the EEG reading room for easy consultation. Physicians requesting an EEG were encouraged to provide more clinical details on the EEG request form. Furthermore, physicians were encouraged to review the EEG with the clinical neurophysiologist whenever possible, especially for difficult or atypical cases or when favouring higher sensitivity (overcalling) rather than higher specificity (undercalling) is warranted. It was also decided to repeat an audit within five years to assess the results of these interventions. Finally, a change in provincial policy may be warranted. For some years now, the national qualifying examination developed by the EEG section of the Canadian Society of Clinical Neurophysiologists EEG is no longer mandatory for graduating neurologists who plan to continue reading EEGs in the province. Audits from other provincial centres could help us determine if this policy should be re-examined to ensure adequate training.

\section{CONCLUSIONS}

Physicians requesting an EEG may rely on an incorrect EEG interpretation to diagnose epilepsy, especially when the clinical event is poorly detailed and lack eyewitness testimony. The misdiagnosis of epilepsy may result in various consequences such as unwarranted treatment with subsequent side effects, loss of driving licence, negative social impact, and loss of work. Until a repeat audit confirms the impact of measures listed above, we recommend that EEG results be interpreted with some caution by those who have requested them. In our quest to improve the overall quality of our EEG laboratory, we have first looked at EEGs reporting temporal abnormalities because we had encountered a few patients midiagnosed as epileptic based on BEVs. Our approach works well for identifying overcalling of EEG abnormalities but does not allow to identify undercalling of important abnormalities. Our next task will be to review all consecutive records to also determine how many temporal abnormalities were originally missed (i.e. false negative).

\section{ACKNOWLEDGEMENTS}

The authors thank the personnel of the Notre-Dame EEG laboratory, all patients and their treating neurologists. Dr. Dang K. Nguyen completed the statistical analysis with the help of Marc Dorais (a consultant in biostatistics for Statsciences Inc.).

\section{REFERENCES}

1. Houfek EE, Ellingson RJ. On the reliability of clinical EEG interpretation. J Nerv Ment Dis. 1959; 128: 425-37.

2. Little SC, Raffel SC. Intra-rater reliability of EEG interpretations. J Nerv Ment Dis. 1962; 135: 77-81.

3. Woody RH. Inter-judge reliability in clinical electroencephalography. J Clin Psychol. 1968; 24: 251-6.

4. Wilson SB, Harner RN, Duffy FH, Tharp BR, Nuwer MR, Sperling MR. Spike detection I. Correlation and reliability of human experts. Electroenceph Clin Neurophysiol. 1996; 98: 186-98.

5. Gilbert DL, Sethuraman G, Kotagal U, Buncher CR. Meta-analysis of EEG test performance shows wide variation among studies. Neurology. 2002; 60: 54-7.

6. Beun AM, Van Emde Boas W, Dekker E. Sharp transients in the sleep of healthy adults: a possible pitfall in the diagnostic assessment of seizure disorders. Electroenceph Clin Neurophysiol. 1998; 106: 44-51.

7. Mushtaq R, Van Cott AC. Benign EEG variants. Am J Electroneurodiagnostic Technol. 2005; 45: 88-101.

8. Tatum IV WO, Husain AM, Bendadis SR, Kaplan PW. Normal adult EEG and patterns of uncertain significance. J Clin Neurophysiol. 2006; 23: 194-207. 
Appendix

Results of EEG interpretation by two epileptologists on two different sittings, six months apart

\begin{tabular}{|c|c|c|c|c|c|c|c|c|c|c|c|}
\hline $\begin{array}{l}\text { EEG } \\
\text { no. }\end{array}$ & Age & $\begin{array}{l}\text { First reading } \\
\text { (DKN) }\end{array}$ & $\begin{array}{l}\text { 2nd reading } \\
\text { (DKN) }\end{array}$ & $\begin{array}{l}\text { 1st reading } \\
\text { (JMSH) }\end{array}$ & $\begin{array}{l}\text { 2nd reading } \\
\text { (JMSH) }\end{array}$ & $\begin{array}{l}\text { EEG } \\
\text { no. }\end{array}$ & Age & $\begin{array}{l}\text { First reading } \\
\text { (DKN) }\end{array}$ & $\begin{array}{l}\text { 2nd reading } \\
\text { (DKN) }\end{array}$ & $\begin{array}{l}\text { 1st reading } \\
\text { (JMSH) }\end{array}$ & $\begin{array}{l}\text { 2nd reading } \\
\text { (JMSH) }\end{array}$ \\
\hline 1 & 75 & 1 & 1 & 1 & 1 & 73 & 72 & 4 & 4 & 4 & 1 \\
\hline 2 & 61 & 3 & 3 & 3 & 3 & 74 & 42 & 3 & 3 & 2 & 3 \\
\hline 3 & 66 & 2 & 2 & 2 & 2 & 75 & 42 & 4 & 4 & 4 & 3 \\
\hline 4 & 74 & 2 & 1 & 2 & 2 & 76 & 78 & 2 & 2 & 2 & 2 \\
\hline 5 & 20 & 3 & 3 & 3 & 3 & 77 & 60 & 1 & 1 & 1 & 1 \\
\hline 6 & 21 & 3 & 3 & 3 & 3 & 78 & 60 & 1 & 1 & 1 & 1 \\
\hline 7 & 56 & 2 & 2 & 4 & 2 & 79 & 79 & 3 & 3 & 3 & 3 \\
\hline 8 & 42 & 3 & 3 & 3 & 3 & 80 & 65 & 3 & 3 & 3 & 3 \\
\hline 9 & 47 & 1 & 1 & 4 & 1 & 81 & 50 & 3 & 3 & 3 & 3 \\
\hline 10 & 32 & 3 & 3 & 3 & 3 & 82 & 40 & 4 & 4 & 4 & 4 \\
\hline 11 & 69 & 3 & 3 & 3 & 3 & 83 & 60 & 3 & 4 & 3 & 3 \\
\hline 12 & 60 & 2 & 2 & 3 & 4 & 84 & 60 & 3 & 3 & 3 & 3 \\
\hline 13 & 37 & 4 & 4 & 4 & 3 & 85 & 50 & 4 & 1 & 3 & 1 \\
\hline 14 & 63 & 3 & 3 & 3 & 3 & 86 & 21 & 3 & 4 & 3 & 3 \\
\hline 15 & 59 & 3 & 3 & 3 & 3 & 87 & 62 & 1 & 1 & 2 & 2 \\
\hline 16 & 59 & 3 & 3 & 3 & 3 & 88 & 60 & 3 & 3 & 3 & 3 \\
\hline 17 & 69 & 4 & 4 & 3 & 4 & 89 & 58 & 3 & 3 & 3 & 3 \\
\hline 18 & 66 & 2 & 3 & 3 & 2 & 90 & 51 & 2 & 2 & 2 & 3 \\
\hline 19 & 41 & 3 & 3 & 3 & 3 & 91 & 61 & 3 & 1 & 3 & 3 \\
\hline 20 & 28 & 2 & 3 & 2 & 3 & 92 & 83 & 3 & 3 & 4 & 2 \\
\hline 21 & 60 & 1 & 1 & 1 & 2 & 93 & 49 & 1 & 1 & 3 & 3 \\
\hline 22 & 43 & 1 & 1 & 1 & 1 & 94 & 68 & 1 & 1 & 3 & 1 \\
\hline 23 & 58 & 3 & 3 & 3 & 3 & 95 & 87 & 3 & 3 & 3 & 4 \\
\hline 24 & 84 & 1 & 1 & 4 & 2 & 96 & 75 & 2 & 1 & 2 & 4 \\
\hline 25 & 40 & 1 & 1 & 1 & 1 & 97 & 71 & 1 & 1 & 1 & 1 \\
\hline 26 & 27 & 1 & 1 & 1 & 1 & 98 & 54 & 3 & 3 & 3 & 3 \\
\hline 27 & 36 & 3 & 4 & 3 & 3 & 99 & 57 & 1 & 3 & 1 & 4 \\
\hline 28 & 60 & 3 & 3 & 3 & 3 & 100 & 34 & 1 & 1 & 1 & 1 \\
\hline 29 & 36 & 3 & 4 & 3 & 3 & 101 & 75 & 2 & 2 & 4 & 2 \\
\hline 30 & 29 & 1 & 1 & 1 & 1 & 102 & 51 & 3 & 3 & 3 & 3 \\
\hline 31 & 31 & 3 & 3 & 3 & 3 & 103 & 40 & 1 & 4 & 4 & 1 \\
\hline 32 & 49 & 3 & 3 & 3 & 2 & 104 & 36 & 3 & 3 & 3 & 3 \\
\hline 33 & 74 & 3 & 3 & 3 & 3 & 105 & 51 & 3 & 3 & 3 & 3 \\
\hline 34 & 68 & 3 & 3 & 3 & 2 & 106 & 43 & 3 & 3 & 4 & 3 \\
\hline 35 & 41 & 4 & 4 & 3 & 1 & 107 & 46 & 1 & 1 & 1 & 1 \\
\hline 36 & 51 & 4 & 4 & 1 & 3 & 108 & 26 & 3 & 3 & 3 & 3 \\
\hline 37 & 62 & 3 & 3 & 3 & 3 & 109 & 59 & 1 & 1 & 1 & 1 \\
\hline 38 & 82 & 3 & 3 & 3 & 1 & 110 & 57 & 3 & 3 & 3 & 3 \\
\hline 39 & 66 & 4 & 4 & 4 & 1 & 111 & 47 & 1 & 3 & 3 & 3 \\
\hline 40 & 68 & 1 & 1 & 3 & 1 & 112 & 34 & 1 & 1 & 4 & 2 \\
\hline 41 & 18 & 1 & 1 & 1 & 1 & 113 & 46 & 3 & 0 & 0 & 3 \\
\hline 42 & 65 & 3 & 3 & 3 & 3 & 114 & 94 & 3 & 3 & 4 & 4 \\
\hline 43 & 73 & 3 & 3 & 3 & 3 & 115 & 63 & 3 & 3 & 3 & 3 \\
\hline 44 & 81 & 3 & 3 & 3 & 3 & 116 & 59 & 1 & 1 & 3 & 1 \\
\hline 45 & 43 & 1 & 1 & 1 & 1 & 117 & 77 & 3 & 3 & 3 & 1 \\
\hline 46 & 29 & 3 & 3 & 3 & 3 & 118 & 80 & 2 & 2 & 0 & 2 \\
\hline 47 & 78 & 2 & 1 & 2 & 2 & 119 & 57 & 1 & 1 & 0 & 1 \\
\hline 48 & 29 & 3 & 4 & 4 & 4 & 120 & 47 & 3 & 3 & 3 & 3 \\
\hline 49 & 33 & 3 & 3 & 3 & 3 & 121 & 25 & 3 & 4 & 3 & 4 \\
\hline 50 & 62 & 1 & 3 & 3 & 1 & 122 & 26 & 3 & 3 & 3 & 3 \\
\hline 51 & 76 & 2 & 2 & 2 & 2 & 123 & 70 & 3 & 3 & 3 & 3 \\
\hline 52 & 50 & 3 & 3 & 3 & 3 & 124 & 34 & 4 & 2 & 4 & 2 \\
\hline 53 & 46 & 1 & 1 & 1 & 1 & 125 & 64 & 1 & 1 & 1 & 1 \\
\hline 54 & 17 & 1 & 2 & 4 & 2 & 126 & 91 & 2 & 3 & 2 & 2 \\
\hline 55 & 74 & 4 & 3 & 3 & 4 & 127 & 76 & 2 & 3 & 2 & 3 \\
\hline 56 & 52 & 2 & 4 & 2 & 2 & 128 & 19 & 1 & 1 & 1 & 1 \\
\hline 57 & 17 & 2 & 1 & 2 & 2 & 129 & 79 & 2 & 4 & 2 & 2 \\
\hline 58 & 52 & 3 & 3 & 4 & 3 & 130 & 86 & 2 & 2 & 2 & 2 \\
\hline 59 & 68 & 2 & 2 & 2 & 0 & 131 & 43 & 3 & 3 & 3 & 3 \\
\hline 60 & 51 & 1 & 1 & 1 & 1 & 132 & 76 & 1 & 1 & 3 & 3 \\
\hline 61 & 94 & 3 & 3 & 3 & 3 & 133 & 82 & 3 & 3 & 1 & 1 \\
\hline 62 & 48 & 3 & 3 & 3 & 3 & 134 & 47 & 3 & 4 & 4 & 1 \\
\hline 63 & 38 & 1 & 1 & 1 & 1 & 135 & 78 & 2 & 2 & 0 & 2 \\
\hline 64 & 46 & 1 & 1 & 1 & 1 & 136 & 55 & 3 & 3 & 3 & 3 \\
\hline 65 & 21 & 3 & 3 & 4 & 1 & 137 & 67 & 3 & 3 & 3 & 3 \\
\hline 66 & 22 & 3 & 4 & 4 & 3 & 138 & 60 & 1 & 1 & 0 & 1 \\
\hline 67 & 32 & 0 & 0 & 0 & 2 & 139 & 48 & 1 & 1 & 1 & 1 \\
\hline 68 & 64 & 1 & 1 & 1 & 1 & 140 & 36 & 3 & 3 & 3 & 3 \\
\hline 69 & 23 & 2 & 1 & 1 & 3 & 141 & 65 & 1 & 1 & 4 & 1 \\
\hline 70 & 53 & 1 & 1 & 1 & 1 & 142 & 22 & 1 & 1 & 1 & 1 \\
\hline 71 & 34 & 3 & 3 & 3 & 3 & 143 & 73 & 3 & 3 & 3 & 3 \\
\hline 72 & 72 & 2 & 2 & 2 & 2 & & & & & & \\
\hline
\end{tabular}

$0=$ uninterpretable; 1 = epileptic activity; 2 = pathological slowing; 3 = normal or benign variants; 4 = suspicious for epileptic spike 
9. Krauss GL, Abdallah BA, Lesser R, Thompson RE, Niedermeyer E. Clinical and EEG features of patients with EEG wicket rhythms misdiagnosed with epilepsy. Neurology. 2005; 64: 1879-83.

10. Westmoreland BF, Klass DW. Unusual variants of subclinical rhythmic electrographic discharge of adults (SREDA). Electroencephal Clin Neurophysiol. 1997; 102: 1-4.

11. Radhakrishnan K, Santoshkumar B, Venugopal A. Prevalence of benign epileptiform variants observed in an EEG laboratory from South India. Clin Neurophysiol. 1999; 110: 280-5.

12. Smith D, Defalla BA, Chadwick DW. The misdiagnosis of epilepsy and the management of refractory epilepsy in a specialist clinic. Q J Med. 1999; 92: 15-23.

13. Santoshkumar B, Chong JJR, Blume WT, et al. Prevalence of benign epileptiform variants. Clin Neurophysiol. 2002; 120: 856-61.

14. American Clinical Neurophysiology Society Guidelines (Numbers 1-8). J Clin Neurophysiol. 2006; 23(2): 85-124.
15. Minimal Standards for Electroencephalography in Canada, 2002 Minimal Standards for Electroencephalography in Canada. Prepared by a Task Force of The Canadian Society of Clinical Neurophysiologists. Can J Neurol Sci. 2002; 29: 216-20.

16. Atlas of adult electroencephalography. 2nd ed. Blume WT, Kaibara M, Young GB, editors. Philadelphia: Lippincott Williams \& Wilkins; 2002.p.?

17. Landis JR, Koch GG. The measurement of observer agreement for categorical data. Biometrics. 1977; 33(1): 159-74.

18. Van Donselaar CA, Schimsheimer RJ, Geerts AT, Declerck AC. Value of the electroencephalogram in adult patients with untreated idiopathic first seizures. Arch Neurol. 1992; 49(3): 231-7.

19. Piccinelli P, Viri M, Zucca C et al. Inter-rater reliability of the EEG reading in patients with childhood idiopathic epilepsy. Epilepsy Res. 2005; 66: 195-8. 